\title{
Caracterização das lesões por Cysticercus bovis, na inspeção post mortem de bovinos, pelos exames macroscópico, histopatológico e pela reação em cadeia da polimerase (PCR) ${ }^{1}$
}

\author{
Renata F.R. Costa ${ }^{2 *}$, Iacir F. Santos ${ }^{3}$, Angela Patricia Santana ${ }^{4}$, Rogerio Tortelly ${ }^{5}$, Elmiro \\ R. Nascimento ${ }^{2}$, Rubens T. Fukuda ${ }^{6}$, Eulógio C.Q. Carvalho ${ }^{7}$ e Rodrigo C. Menezes ${ }^{8}$
}

\begin{abstract}
Costa R.F.R., Santos I.F., Santana A.P., Tortelly R., Nascimento E.R., Fukuda R.T., Carvalho E.C.Q. \& Menezes R.C. 2012. [Characterization of Cysticercus bovis lesions at postmortem inspection of cattle by gross examination, histopathology and polymerase chain reaction (PCR).] Caracterização das lesões por Cysticercus bovis, na inspeção post mortem de bovinos, pelos exames macroscópico, histopatológico e pela reação em cadeia da polimerase (PCR). Pesquisa Veterinária Brasileira 32(6):477-484. Departamento de Saúde Coletiva Veterinária e Saúde Pública, Faculdade de Veterinária, Universidade Federal Fluminense, Rua Vital Brazil Filho 64, Santa Rosa, Niterói, RJ 24230-340, Brazil. E-mail: rrfalcosta@yahoo.com.br

Considering the importance of improving methods for diagnosis of bovine Cysticercosis, this study aimed to verify Cysticercus bovis occurrence in different anatomical sites, as head, heart, esophagus, diaphragm, tongue, liver and carcass, examined by federal inspection service. Diagnosis was performed by gross examination, histopatholgy and PCR with boiling DNA extraction for metacestode identification. Of 22043 slaughtered cattle, 713 (3.23\%) were infected. The heart was mostly affected with $1.90 \%$ (420/22043), followed by head, $1.11 \%$ (245/22043), esophagus, $0.08 \%$ (18/22043), carcass, $0.07 \%(15 / 22043)$, diaphragm, $0.03 \%$ (7/22043), liver, $0.02 \%(5 / 22043)$ and tongue, $0.01 \%(3 / 22043)$. Of the cysts obtained, $58.35 \%$ (416/713) were dead and $41.65 \%(297 / 713)$ were alive. The differences among anatomical sites and cysts status were significant $(p<0.05)$. Of the 416 dead cysts 253 , characterized by nodular firm whitish lesions, containing yellowish material, some times in calcareous aspect were examined for histopathology. The histological exams of these cysts yielded granulomatous lesions, whose centers were characterized by caseous and/or calcareous material, multinucleate giant cells, histiocytes in palisade and infiltrate composed predominantly by lymphoid cells, wrapped up by fibrosis. Some times the lesions peripheries had granulation tissue and mineralized areas, like linear blade. The parasite debris were like a hyaline, non cellular material with spherical and ovoid, basophilic, eosinophilic and colorless corpuscles. These corpuscles were seen rarely, some times, among inflammatory reaction. Fibrous nodules, rich in lymphoid or mixed infiltrates, were frequently seen. Of the live cysts subjected to PCR with boiling DNA extraction, 65\%
\end{abstract}

\footnotetext{
${ }^{1}$ Recebido em 8 de outubro de 2011.

Aceito para publicação em 3 de janeiro de 2012.

${ }^{2}$ Departamento de Saúde Coletiva Veterinária e Saúde Pública, Faculdade de Veterinária, Universidade Federal Fluminense (UFF), Rua Vital Brazil Filho 64, Santa Rosa, Niterói, RJ 24230-340, Brasil.*Autor para correspondência: rrfalcosta@yahoo.com.br

${ }^{3}$ Departamento de Tecnologia de Alimentos, Faculdade de Veterinária, UFF, Niterói, RJ.

${ }^{4}$ Laboratório de Microbiologia Molecular de Alimentos, ASS 128/10, Faculdade de Agronomia e Medicina Veterinária, Universidade de Brasília (UnB), Campus Universitário Darcy Ribeiro, Asa Norte, Instituto Central de Ciências Ala Sul, Cx. Postal 4.508, Brasília, DF 70910-970, Brasil.
}

\footnotetext{
${ }^{5}$ Pro-Reitoria de Extensão (UFF), Rua Miguel de Frias 9, Icaraí, Niterói, RJ 24220-008.

${ }^{6}$ Superintendência Federal de Agricultura, Ministério da Agricultura, Pecuária e Abastecimento, Praça Francisco Barreto 125, Centro, Barretos, SP 14780-059, Brasil.

${ }^{7}$ Laboratório de Sanidade Animal, Centro de Ciências e Tecnologias Agropecuárias, Universidade Estadual do Norte Fluminense (UENF), Av. Alberto Lamego 2.000, Horto, Campos dos Goytacazes, RJ 28.013-600, Brasil.

${ }^{8}$ Instituto de Pesquisa Clínica Evandro Chagas (IPEC), Fundação Instituto Oswaldo Cruz (Fiocruz), Av. Brasil 4365, Manguinhos, Rio de Janeiro, RJ 21040-360, Brasil.
} 
$(13 / 20)$ were positive for $C$. bovis, confirming the ambulatory diagnosis and the efficacy of the PCR procedure used. Due to microscopic and PCR diagnostic exams of $C$. bovis, mainly in the liver and esophagus, it is suggested changes in the 176 article of the regulatory inspection, by including these sites in the bovine routine inspection at the slaughterhouses.

INDEX TERMS: Cysticercus bovis, Taenia saginata, cattle, cysticercosis, sanitary inspection, histopathology, PCR.

RESUMO.- Considerando a necessidade do conhecimento da cisticercose bovina e do aperfeiçoamento dos métodos de diagnóstico desta doença, objetivou-se verificar a ocorrência do Cysticercus bovis nos diversos locais anatômicos, tais como: cabeça, coração, esôfago, diafragma, língua, fígado e carcaça, examinados pelo Serviço de Inspeção Federal. O diagnóstico foi feito por macroscopia, microscopia e PCR com extração de DNA por fervura para a identificação do metacestóide. Dos 22043 bovinos abatidos, 713 (3,23\%) estavam infectados. 0 coração foi o sítio anatômico mais afetado, com 1,90\% (420/22043), seguido da cabeça, 1,11\% (245/22043), do esôfago, 0,08\% (18/22043), da carcaça, $0,07 \%$ (15/22043), do diafragma, 0,03\% (7/22043), do fígado, $0,02 \%(5 / 22043)$ e da língua, $0,01 \%(3 / 22043)$. Dos cistos obtidos, $58,35 \%$ (416/713) estavam mortos e $41,65 \%$ (297/713), vivos. As diferenças entre os sítios anatômicos e a condição morfológica dos cistos foram significativas ( $p$ $<0,05$ ). Dos 416 cistos mortos, 253 foram examinados por apresentarem características de: lesões nodulares firmes, brancacentas, com material amarelado, por vezes com aspecto calcário, no interior. 0 exame microscópico revelou granulomas comumente representados por centro necrótico e/ou mineralizado, envolto por histiócitos dispostos em paliçada, células gigantes multinucleadas, infiltrado misto, predominantemente de mononucleares, e fibrose. Por vezes, a periferia das lesões tinha características de tecido de granulação e mineralização em forma de lâminas lineares. Os restos parasitários foram identificados como um material hialino acelular, contendo elementos ovais e circulares, basofílicos, acidófilos e incolores, denominados corpúsculos calcários. Em algumas lesões foram observados raros corpúsculos, dispersos na reação inflamatória. Nódulos fibrosos, ricos em infiltrado linfóide ou crônico ativos, foram frequentemente visualizados. Dos cistos vivos examinados, $65 \%(13 / 20)$ foram positivos para C. bovis , confirmando o diagnóstico ambulatorial e a eficácia do método de PCR utilizado. Em virtude da positividade observada para C. bovis nos exames histopatológico e PCR, particularmente em fígado e esôfago, sugere-se que seja reformulado o artigo 176 do Regulamento de Inspeção Industrial e Sanitária de Produtos de Origem Animal, incluindo estes locais na rotina de inspeção nos matadouros.

TERMOS DE INDEXAÇÃO: Cysticercus bovis, Taenia saginata, bovino, cisticercose, inspeção sanitária, histopatologia, PCR.

\section{INTRODUÇÃO}

A cisticercose no Brasil é a zoonose de maior ocorrência no exame post mortem de bovinos, revestindo-se de importância socioeconômica e de Saúde Pública (Santos 1993). Esta parasitose, além de envolver vultosos gastos com o tratamento e as condenações de carnes infectadas com
Cysticercus bovis, forma larvar de Taenia saginata, acarreta prejuízos para o pecuarista e restringe a comercialização dos frigoríficos, particularmente em relação ao mercado externo (Fukuda 2003).

A fase adulta deste cestóide, ou seja, a tênia, ocorre no trato intestinal do homem, podendo provocar debilidade e diminuição da capacidade de trabalho dos indivíduos afetados (Abdussalam 1974). A fonte de infecção neste caso é a ingestão de carne crua ou insuficientemente cozida, de bovinos que contraíram a cisticercose através de alimentos e água contaminados com ovos provenientes das fezes humanas.

Sendo a carne a fonte de infecção humana, muitos pesquisadores destacam a importância da inspeção sanitária na busca dos cistos parasitários em carcaças, órgãos e vísceras, aliada ao aprimoramento e a padronização das técnicas usadas neste diagnóstico e a definição da maior distribuição dos cisticercos no corpo do animal (locais de predileção).

Não há dificuldade para o diagnóstico macroscópico de C. bovis no seu estádio larval vivo. Todavia, este diagnóstico pode ser dificultado nos casos em que os metacestóides estejam mortos (em lesões abscedadas e mineralizadas). Nestas circunstâncias, o apoio do exame histopatológico pode ser de grande valia na diferenciação de patologias assemelhadas (Costa et al. 2006), como por exemplo, lesões provocadas pela migração de larvas de helmintos, que não o cisticerco, e até mesmo a tuberculose (Monlux \& Monlux 1972, Kelly 1997).

Além do apoio anatomopatológico, o uso da_técnica de reação em cadeia da polimerase (PCR), a partir de primers espécie-específicos, torna possível a identificação rápida e específica de cestóides (González et al. 2000), tendo aplicação potencial no diagnóstico e na diferenciação entre as tênias humanas.

A identificação correta dos cisticercos é importante para os estudos epidemiológicos, tendo em vista a descoberta de uma nova tênia, Taenia asiatica (Bowles \& McManus 1994, McManus \& Bowles 1994, Galán-Puchades \& Mas-Coma 1996) $)_{2}$ que é morfologicamente semelhante a $T$. saginata (Fan et al. 1995), além de espécies em hospedeiros não habituais (Fan et al. 1990, Eom et al. 1992, Gusso et al. 2000, Logt \& Gottstein 2000).

Considerando a necessidade de aperfeiçoamento dos métodos de diagnóstico da cisticercose bovina, objetivou-se verificar a ocorrência do Cysticercus bovis nos diversos locais anatômicos examinados pelo Serviço de Inspeção, caracterizando as lesões do ponto de vista anatomopatológico e identificando a espécie do metacestóide pela técnica da PCR, usando a fervura no protocolo de extração de DNA. 


\section{MATERIAL E MÉTODOS}

Foram examinados pelo Serviço de Inspeção Federal da Indústria e Comércio de Carnes Minerva Ltda (S.I.F. no 421), em Barretos/ SP, 22.043 bovinos machos e fêmeas, de grupo etário variando entre dois a cinco anos, procedentes de várias regiões dos Estados de São Paulo, Minas Gerais e Goiás.

Foram colhidas, aleatoriamente, amostras de lesões císticas e nodulares, compatíveis com cisticercose, para cada local examinado, a saber: cabeça, coração, esôfago, diafragma, língua, fígado e carcaça, conforme a positividade relacionada à execução do exame post mortem de rotina, baseado na legislação vigente (Brasil $1971,1997)$ e nas técnicas desenvolvidas por Santos $(1982,1984)$ de exame de coração e de esôfago e diafragma, respectivamente.

No Departamento de Inspeção Final (D.I.F.) os fragmentos foram separados de acordo com o tipo de análise, condição morfológica dos cistos (viáveis e inviáveis) e localização.

Foram considerados como cisticercos viáveis, as lesões císticas com parede translúcida ou levemente opaca, contendo líquido claro e um ponto esbranquiçado no interior (escólex). As lesões nodulares foram reputadas como cisticercos inviáveis (mortos), caracterizando-se por terem cápsula fibrosa aderente ao tecido circunvizinho contendo material amarelado caseoso e/ou calcário.

Para análise histopatológica, 253 lesões nodulares foram fixadas em solução de formol a $10 \%$, remetidas ao Serviço de Anatomia Patológica Veterinária Professor Jefferson Andrade dos Santos, da Universidade Federal Fluminense, para processamento habitual de inclusão em parafina, coloração pela hematoxilina-eosina (HE) e exame em microscopia óptica.

Do total das amostras colhidas, 39 foram provenientes da cabeça, 158 do coração, quatro do esôfago, uma do diafragma, uma de carcaça, duas de língua e 48 de fígado.

Para a realização da técnica da PCR, 20 lesões císticas (nove localizadas em cabeça, sendo seis em músculo masseter e três em músculo pterigóide; oito em coração, uma em esôfago, uma em fígado e uma em carcaça) foram dissecadas, colocadas em frascos com solução de glicerol em salina tamponada fosfatada (PBS), $\mathrm{pH}$ 7.4 , a $50 \%$ e armazenadas em freezer $\left(-20^{\circ} \mathrm{C}\right)$, por três anos.

A extração de DNA foi feita por fervura, após a lavagem dos cistos, para a eliminação do conservante, seguida da sua abertura, retirada e maceração do seu conteúdo (escólex).

A amplificação do DNA foi realizada através da execução do HDP2-PCR, a partir de primers previamente descritos por Gonzaléz et al. (2000), sintetizados por Integrated DNA Technologies, Inc. (IDT)/USA, Prodimol Biotecnologia S/A, Brasil. Os amplicons foram separados em gel de agarose a $1,5 \%$ com brometo de etídio a $0,02 \%$ e visualizados sob luz ultravioleta.

\section{RESULTADOS E DISCUSSÃO}

A prevalência da cisticercose observada foi de 3,23\% (713/22043), bem inferior aos $17,14 \%$ e $8,90 \%$, respectivamente, em outubro de 1993 e 1994, observadas por Fukuda et al. (1998), no matadouro situado em Ipuã, SP. 0 coração foi o sítio anatômico mais afetado, com 1,90\% (420/22.043), seguido da cabeça, 1,11\% (245/22043), do esôfago, 0,08\% (18/22043), da carcaça 0,07\% (15/22043), do diafragma $0,03 \%(7 / 22043)$, do fígado $0,02 \%(5 / 22043)$ e da língua $0,01 \%(3 / 22043)$. Pelo teste de Qui-quadrado, houve diferença significativa $(\mathrm{p}<0,05)$, relacionada à distribuição dos casos por sítios anatômicos, indicando que as diferenças de prevalência são reais e não devidas ao acaso (Quadro 1).
Quadro 1. Ocorrência de cisticercose em sítios anatômicos de bovinos monocisticercósicos, abatidos e inspecionados na Indústria e Comércio de Carnes Minerva LTDA (S.I.F. n. 421), em Barretos/SP, durante o mês de outubro de 2004*

\begin{tabular}{lcc}
\hline \multicolumn{1}{c}{ Sítios anatômicos } & $\begin{array}{c}\text { Prevalência em 22.043 } \\
\text { animais abatidos }\end{array}$ & Distribuição de casos \\
\hline Coração & $1,90 \%$ & 420 \\
Músculos mastigatórios & $1,11 \%$ & 245 \\
Esôfago & $0,08 \%$ & 18 \\
Carcaça & $0,07 \%$ & 15 \\
Diafragma & $0,03 \%$ & 07 \\
Fígado & $0,02 \%$ & 05 \\
Língua & $0,01 \%$ & 03 \\
TOTAL & $3,23 \%$ & 713
\end{tabular}

${ }^{*} \chi^{2}$ para independência $(\mathrm{p}<0,05)$.

Constata-se, na literatura, que existem divergências entre autores quanto à localização mais freqüente dos cisticercos. Mas, para a maioria deles, os metacestóides são encontrados principalmente nos músculos melhor irrigados, notadamente no coração, 58.91\% (420/713), e músculos da cabeça, 34,36\% (245/713), como demonstrado neste estudo $(93,27 \%)$.

Ao serem comparadas as prevalências observadas nos diversos locais anatômicos, com os achados de Santos (1982), Santos (1984), Fukuda et al. (1998), Santos et al. (2003), Santos (1993), Moreira et al. (2002) e Costa et al. (2005), pode-se perceber a discrepância de resultados. Contudo, as diferentes taxas de ocorrência da cisticercose numa população ou em localizações anatômicas específicas, não devem ser confrontadas de forma simplória. Vários fatores importantes são atribuídos às divergências, tais como: a procedência dos animais a partir de áreas com elevadas taxas de infecção, a técnica de exame post mortem utilizada e o fator individual (habilidade pessoal e o critério do inspetor).

0 exame do fígado, do esôfago, do diafragma e de seus pilares, com vistas à cisticercose, não fazem parte da rotina de inspeção da maioria dos matadouros de bovinos, pois não constam nas exigências regulamentares. Observa-se, ainda, a falta de uniformidade nos procedimentos de inspeção post mortem e a inadequabilidade de técnicas. Isto é preocupante, uma vez que uma quantidade considerável de carcaças infectadas pode não ser detectada na rotina de inspeção (Abdussalam 1974, McCool 1979, Santos 1984). Considerando esses fatores, ratifica-se a assertiva de Santos (1993) no tocante ao risco de Saúde Pública quando essas matérias-primas são utilizadas em produtos de salsicharia frescais ou na preparação de pratos crus, sem que sejam previamente inspecionados ou devidamente cozidos.

A quantidade de cisticercos mortos, 58,35\% (416/713), foi maior que a de vivos, 41,65\% (297/713), particularmente no coração: $75,96 \%$ (316/416). 0 predomínio da primeira condição está em consonância com os relatos da literatura especializada, sendo averiguada por vários autores, tais como: Santos (1984), Bundza et al. (1988), Manhoso (1996), Fukuda (2003), Santos et al. (2003) e Costa et al. (2005). 0 teste de Qui-quadrado mostrou associação entre a presença dos cistos (vivos ou mortos) e o sítio de predileção considerado no diagnóstico. Mais ainda, houve diferen- 
ça significativa $(p<0,05)$ entre as freqüências encontradas, referentes à condição morfológica e aos sítios anatômicos (Quadro 2).

De acordo com Pawlowski \& Schultz (1972), a longevidade de $C$. bovis depende do tipo de tecido invadido e não é uniforme no mesmo animal. A esse respeito, o predomínio da condição degenerada (morta) no coração está em consonância com os relatos de Mann \& Mann (1947) que verificaram que este é um dos sítios anatômicos onde os cisticercos se calcificam mais rapidamente.

Segundo Santos (1984), não há dificuldade para o diagnóstico macroscópico de C. bovis vivo. Contudo, este diagnóstico pode ser dificultado nos casos em que os cisticercos estejam mortos, ou seja, em lesões abscedadas e mineralizadas, caracterizadas, neste trabalho, como nódulos firmes, brancacentos, com material amarelado no interior (Fig.0102 ). Algumas vezes foram também observados nódulos firmes e brancacentos, sem o material amarelado.

0 exame microscópico dos nódulos caseosos e/ou calcários, presentes nos diversos sítios anatômicos de bovinos, revelou granulomas comumente representados por centro necrótico e/ou mineralizado, envolto por histiócitos dispostos em paliçada, células gigantes multinucleadas, infiltrado misto, predominantemente de mononucleares, e fibrose (Fig.3). Por vezes, a periferia da lesão tinha ca-

\section{Quadro 2. Localização e condição morfológica dos casos de cisticercose detectados em bovinos monocisticercósicos, abatidos e inspecionados na Indústria e Comércio de Carnes Minerva LTDA (S.I.F. n. 421), em Barretos/SP, durante o mês de outubro de 2004*}

\begin{tabular}{lccccc}
\hline Localização/Condição morfológica & \multicolumn{2}{c}{ Cisticerco morto } & & \multicolumn{2}{c}{ Cisticerco vivo } \\
\cline { 2 - 3 } & $\mathrm{N}$ & $\%$ & & $\mathrm{~N}$ & $\%$ \\
\hline Coração & 316 & 75,96 & & 104 & 35,01 \\
Múnculos mastigatórios & 80 & 19,23 & & 165 & 55,55 \\
Esôfago & 11 & 2,64 & & 07 & 2,35 \\
Diafragma & 05 & 1,20 & & 02 & 0,67 \\
Carcaça & 02 & 0,48 & & 13 & 4,37 \\
Fígado & 01 & 0,24 & & 04 & 1,34 \\
Língua & 01 & 0,24 & & 02 & 0,67 \\
TOTAL & 416 & 100 & & 297 & 100
\end{tabular}

${ }^{*} \chi^{2}$ para independência $(\mathrm{p}<0,05)$.

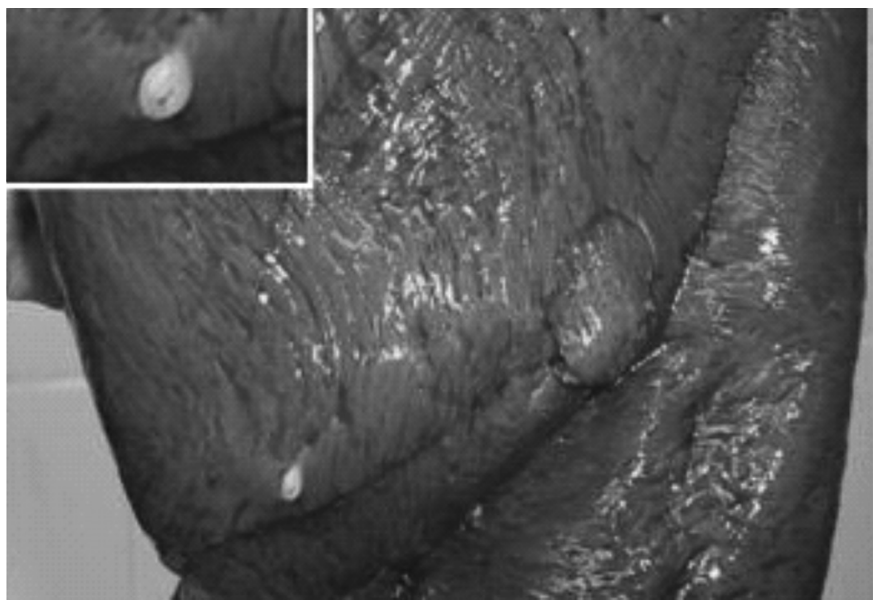

Fig.1. Lesão nodular centralizada por mineralização no miocárdio de bovino com cisticercose.

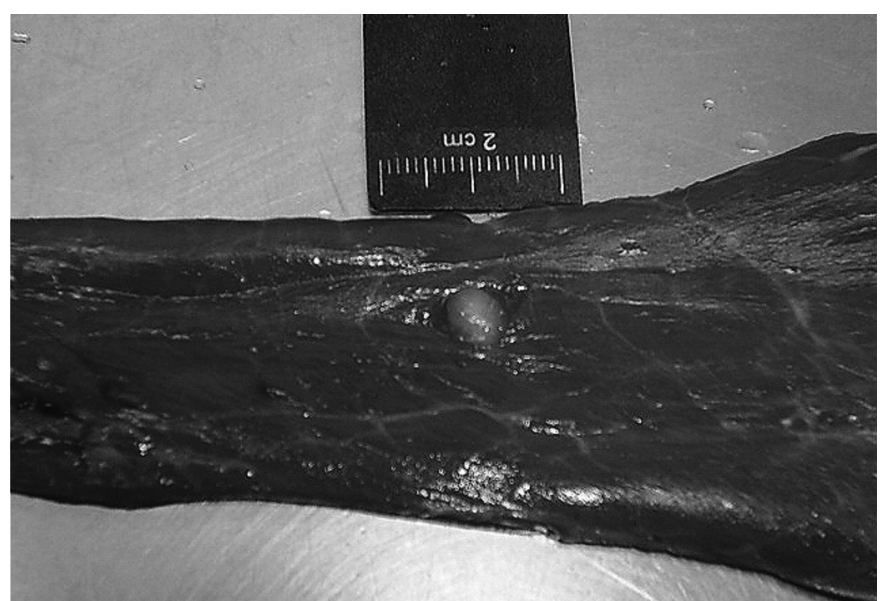

Fig.2. Lesão nodular brancacenta no esôfago de bovino (Cisticerco morto).

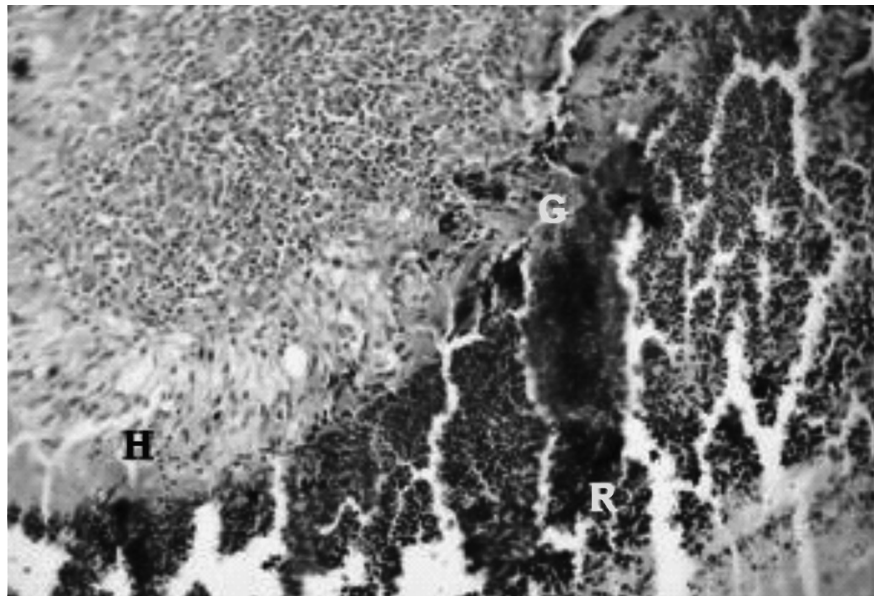

Fig.3. Restos celulares (R) circundados por histiócitos em paliçada $(H)$, parede de células gigantes multinucleadas $(G)$ e infiltrado inflamatório crônico, no miocárdio de bovino com cisticercose. HE, obj.20x.

racterísticas de tecido de granulação e mineralização em forma de lâminas lineares (Fig.04). Os restos parasitários foram identificados como um material hialino acelular contendo elementos ovais e circulares, basofílicos, acidófilos e incolores, denominados corpúsculos calcários (Fig.05-08). Nódulos ricos em tecido fibroso e infiltrado linfóide ou crônico ativo representaram, microscopicamente, as lesões firmes e brancacentas.

As características microscópicas das lesões observadas neste trabalho são comparáveis às descrições de Gibson (1959), Monlux \& Monlux (1972), Sterba \& Dyková (1978a,b), Sterba et al. (1979), Kelly (1997), Costa et al. (2002, 2006) e Tortelly (2003).

Conforme afirmou Santos (1984), nas seções histológicas de cisticercos mortos, apesar da grande alteração dos resquícios parasitários, é possível identificar, na massa de detritos, estruturas ovóides denominadas corpúsculos calcários, em meio à intensa reação inflamatória granulomatosa. Na presente pesquisa, esses corpúsculos foram observados em lesões no músculo mastigatório, coração, fígado e esôfago sendo, por vezes, escassos. Acredita-se que a observação dos elementos característicos esteja vinculada ao 
estágio de evolução do cisticerco, pois com a morte do parasita haveria a fagocitose de seus restos por macrófagos, com subseqüente fibroplasia. Considerando a escassez dos corpúsculos calcários deve-se atentar, principalmente, para aqueles basofílicos de forma circular, pois alguns tinham características psamomatosas que poderiam ser confundidas com pontos de mineralização distrófica. Por sua vez, os corpúsculos incolores poderiam passar despercebidos.

Histiócitos dispostos em paliçada foram observados circundando a área necrótica do exsudato, da mesma maneira que Sterba \& Dyková (1978a), Sterba et al. (1979), Tortelly (2003) e Costa et al. (2006) descreveram. Adjacente a estas células, houve um marcante infiltrado linfocitário, onde notaram-se, muitas vezes, células gigantes multinucleadas, com variações em forma e número de núcleos que se organizavam ora em forma de anel (tipo Langhans) ora em amontoados (tipo corpo estranho) no citoplasma.

Monlux \& Monlux (1972) disseram que as lesões por larvas de helmintos poderiam simular as alterações impu- tadas à tuberculose, enfermidade com características granulomatosas. Todavia, a mineralização linear, bem como os histiócitos em paliçada não são descritos em tal moléstia.

Tortelly (2003) sugeriu que a mineralização em forma linear, em lesões granulomatosas, fosse considerada como uma das características da migração de larvas de helmintos, ao lado dos eosinófilos.

Na etiopatogenia das lesões hepáticas, observa-se que é comum a migração ou mesmo o encistamento de larvas de helmintos. Muitas vezes é atribuída à "hidatidose calcificada" a principal enfermidade implicada quando esse tipo de lesão ocorre em matadouros. A esse respeito, Tortelly (2003) estudou, em fígados de bovinos abatidos em matadouros, 183 lesões nodulares e 37 císticas suspeitas de hidatidose. A análise microscópica das lesões nodulares confirmou apenas dois casos da referida parasitose. Em sete casos foram observados os corpúsculos calcários e os demais foram reputados como migração de larvas de helmintos inespecíficas. Todas as lesões císticas eram cistos congênitos.

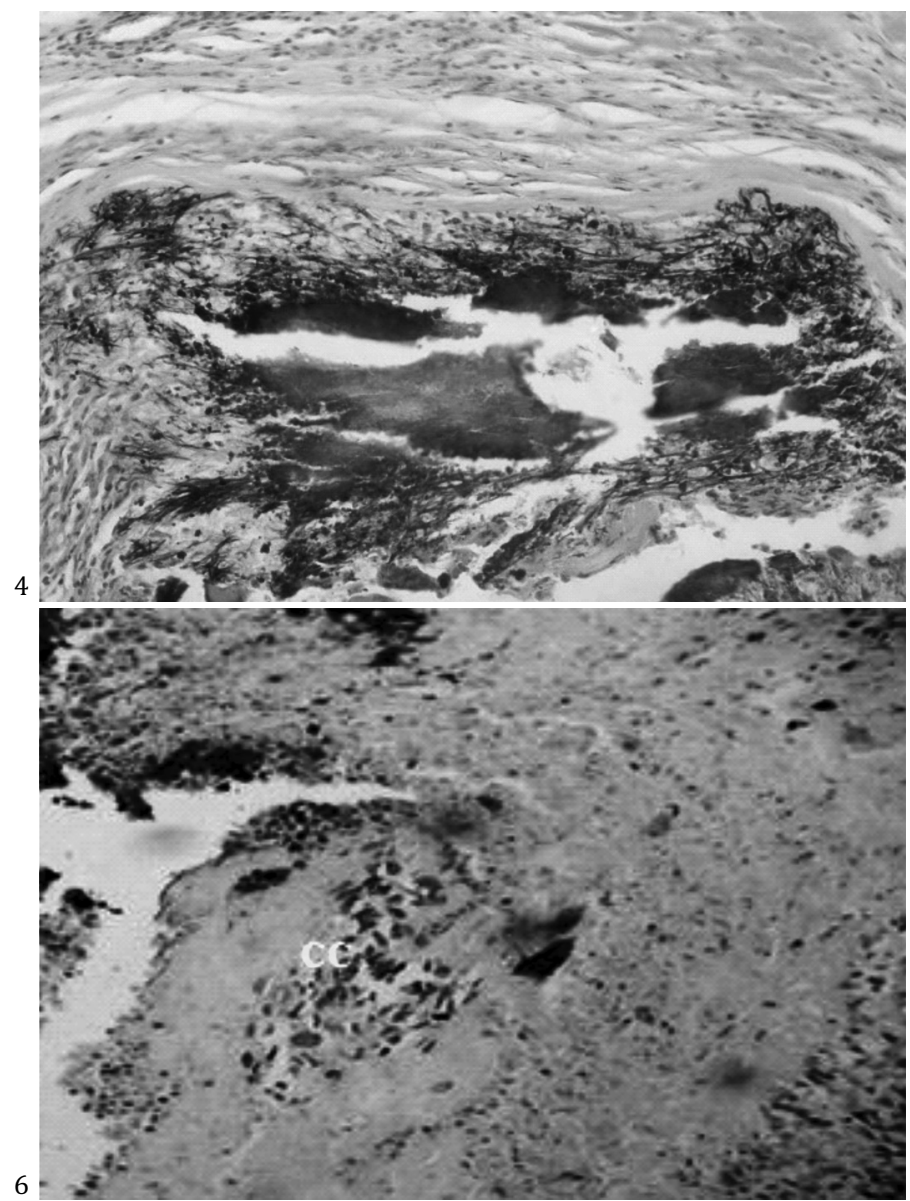

Fig.4. Granuloma centralizado por material calcário (difuso e linear), envolvido por macrófagos, raras células gigantes multinucleadas e cápsula fibrosa com marcante mineralização linear, no miocárdio de bovino com cisticercose. HE, obj 10x.

Fig.6. Os corpúsculos calcários (CC) no parênquima hepático de bovino da figura anterior. HE,obj.20x.

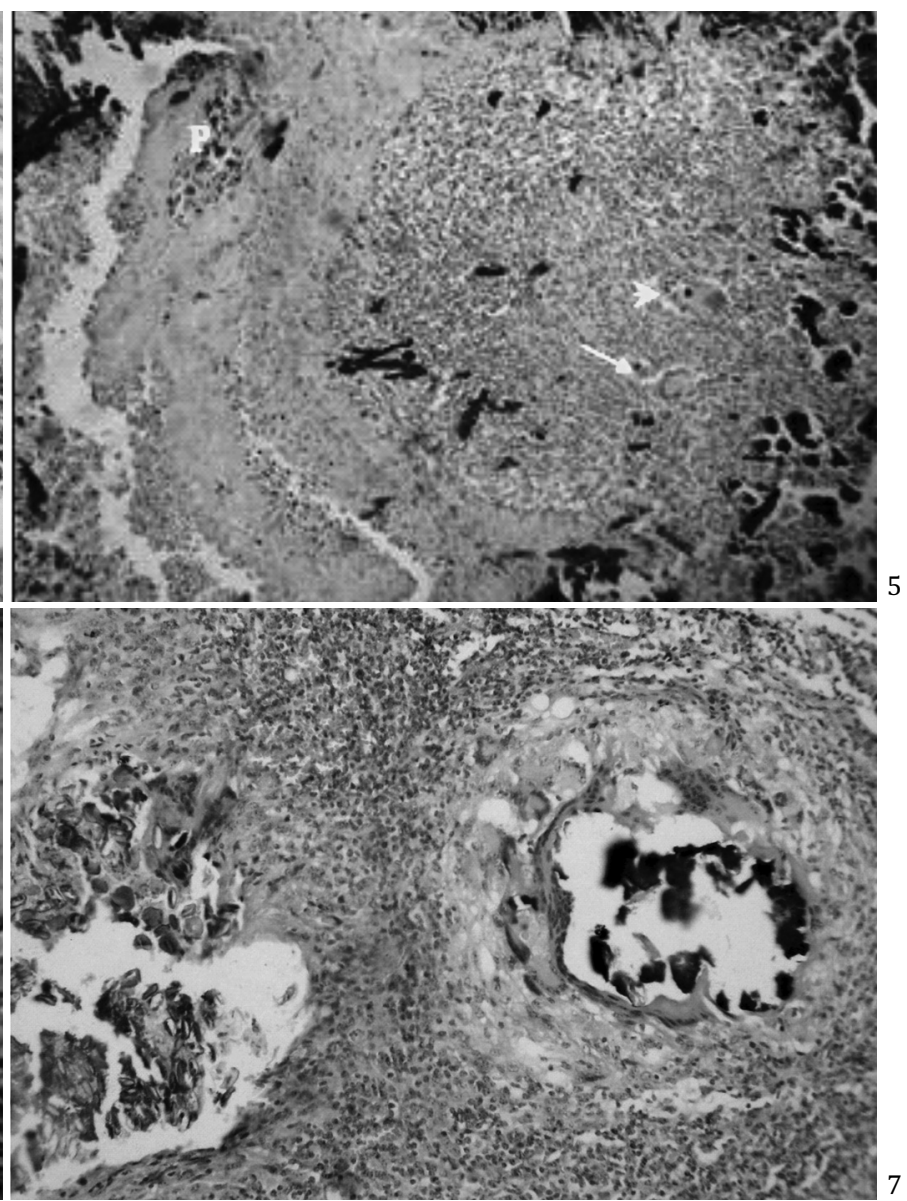

Fig.5. Restos de larva de cestóide no parênquima hepático de bovino, representado por material hialino acelular, com grupo de corpúsculos calcários ovais e esféricos basofilicos (P), adjacente à nódulo linfóide com células epitelióides, células gigantes do tipo Langhans (seta) e de corpo estranho (cabeça de seta) e mineralização. HE, obj.10x.

Fig.7. Corpúsculos calcários levemente basofílicos e incolores (à esquerda) e mineralização envolta por parede de células gigantes multinucleadas (à direita) em meio a infiltrado crônico no miocárdio de bovino. HE, obj.20x. 


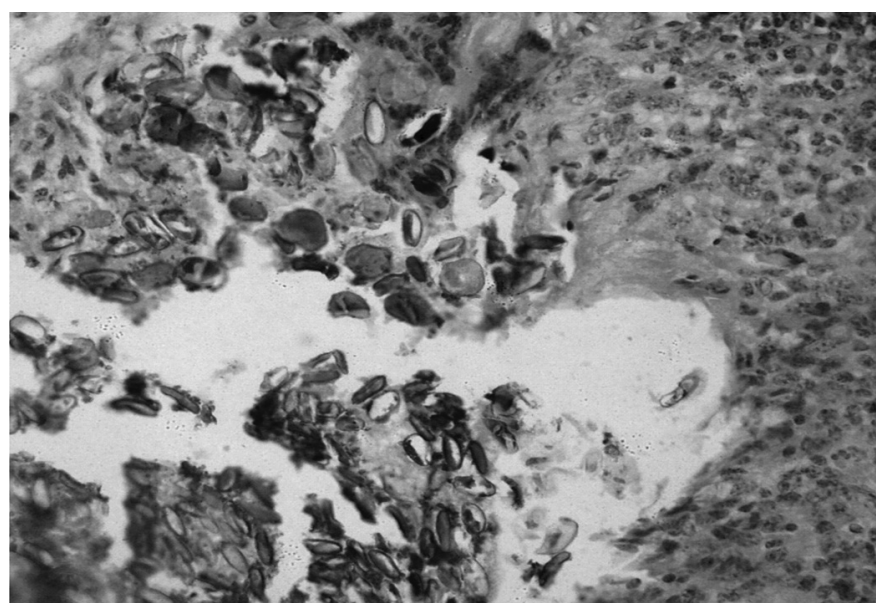

Fig.8. Maior detalhe dos corpúsculos calcários da figura anterior. HE, obj.40x

Como a cisticercose, a prevalência da hidatidose no país é conhecida através dos dados registrados pelos Serviços de Inspeção Sanitária. Sendo assim, seu diagnóstico indiscriminado pode superestimá-la numa dada região. Macroscopicamente, é possível diagnosticá-la em lesões císticas, através da observação da membrana característica. Não obstante, o diagnóstico macroscópico preciso das lesões nodulares hepáticas (abscedadas e calcificadas), de acordo com o autor supracitado, "é praticamente impossível de ser realizado, em virtude da intensa reação inflamatória". Nesta situação o exame histopatológico pode esclarecer dúvidas quanto à natureza e a etiologia dessas lesões, pela visualização de estruturas características: membrana anista na hidatidose e corpúsculos calcários na cisticercose. Entretanto, pode haver, mais uma vez, limitações diagnósticas, pela evolução do processo de interação parasita-hospedeiro culminando com a não evidenciação dos elementos diferenciais.

Dos 297 cistos viáveis encontrados, 20 foram selecionados, ao acaso, de sítios anatômicos variados, tais como: cabeça, coração, carcaça, fígado e esôfago, para confirmar o diagnóstico do S.I.F., através da técnica da PCR. Com o HDP2F1R1-PCR_obteve-se a amplificação desejada (600pb) do material genômico, tanto do controle como das amostras examinadas, em todos os volumes de template testados (2,5uL, 4uL e 6uL), obtendo-se 65\% (13/20) de positividade para Cysticercus bovis. Considerando que as amostras trabalhadas foram conservadas por longo tempo, admite-se que foi um bom resultado (Fig.09).

Quanto à extração de DNA do cestóide em questão, foi unânime a observação, na literatura, de procedimentos baseados em métodos químicos (convencionais), notadamente relacionados à extração por fenol-clorofórmio-álcool isoamílico e precipitação por etanol ou por meio de kits comerciais. Em contrapartida, neste trabalho foi possível demonstrar que a extração de DNA de cisticercos viáveis, por fervura, é um método exeqüível, com resultados satisfatórios. Não há dúvidas que a extração por métodos químicos (Gonzáles et al. 2000, 2002b, 2004, Yamasaki 2004, Jardim 2006, Jardim et al. 2006) produzem resultados convenientes, porém são métodos caros, podem demandar tempo,

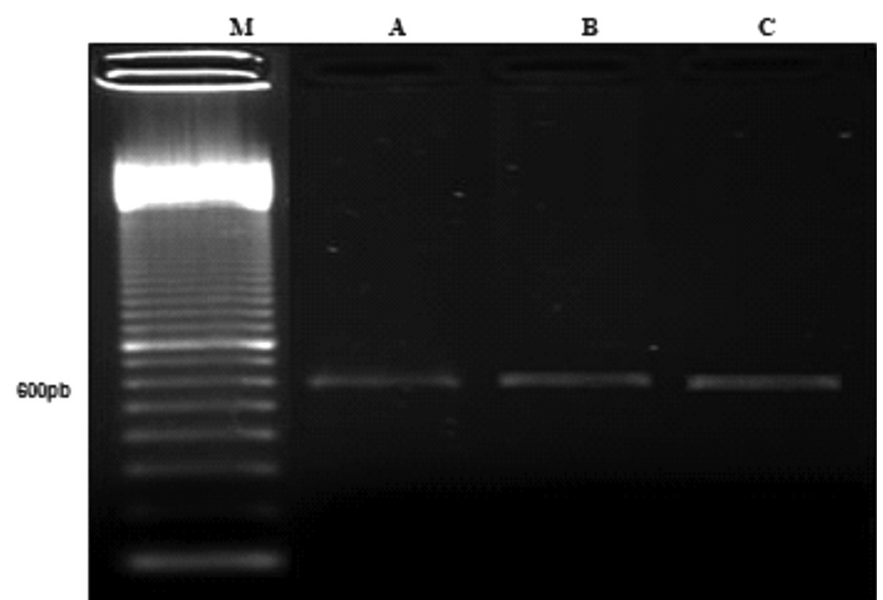

Fig.9. Eletroforese em gel de agarose a 1,5\%, corado com brometo de etídio $0,02 \%$, com produtos de PCR resultantes da amplificação de 2,5uL de gDNA de Cysticercus sp., através do HDP2F1R1-PCR. (M) Marcador de DNA de 100 pb. (A,B) Amostras em teste. (C) gDNA de Taenia saginata (controle).

além de um possível risco para a saúde e para o meio ambiente, devido a alguns reagentes. Pode-se acrescentar que as várias lavagens e centrifugações, exigidas por tais métodos, aumentam o risco de contaminação do template e perda de DNA. A fervura, por sua vez, é simples, barata, rápida e eficaz na identificação de $C$. bovis viáveis.

Ao contrário de Logt \& Gottstein (2000) e Jardim (2006), o exame pela PCR, neste estudo, não foi realizado para o diagnóstico da cisticercose em cistos mortos. Nesse sentido, tendo em vista a problemática do diagnóstico de lesões abscedadas e calcificadas, com ausência dos elementos diferenciais, particularmente no fígado, conforme mencionado anteriormente, acredita-se que este exame também pudesse ser realizado com vistas ao diagnóstico diferencial entre a cisticercose e a hidatidose, uma vez que o HDP2-PCR multiplex, identifica os três tenídeos: Taenia saginata, T. solium e Echinococcus granulosus.

Em relação aos resultados negativos (quatro amostras de músculos mastigatórios e três de coração), muitos fatores podem ter interferido, tais como: o conservante glicerol (poderia ser um inibidor), o tempo de estocagem (três anos em solução de glicerol e PBS a 50\%, em temperatura de congelamento), a maceração inadequada do escólex (liberação insuficiente de gDNA), ou mesmo a ausência do DNA alvo, porque $C$. bovis não era o agente etiológico presente nas lesões.

Yamasaki et al. (2004) admitiram que a sensibilidade da técnica da PCR pudesse ficar reduzida, dependendo das condições e do tempo de armazenamento e também da quantidade de amostra usada.

Considerando a maior prevalência de teníase por T. saginata (Dias et al. 1991, Esteves et al. 2005), bem como a similaridade morfológica entre T. saginata e T. asiatica (Eom \& Rim, 1993, Fan et al. 1995), que é considerada exótica no país, aliadas à endemicidade de cisticercose humana em muitos estados brasileiros (Machado et al. 1988, Agapejev 1996, Takayanagui \& Leite 2001, Mendes et al. 2005) e às baixas taxas de ocorrência da cisticercose suína (Alves 
2000, Flavigna-Guilherme et al. 2006), ao contrário do que se observa em bovinos, torna-se imperiosa a necessidade de aprofundar as análises moleculares, com vistas ao esclarecimento de muitos pontos controversos que permanecem no universo científico, a começar com a possibilidade dos ovos de T. saginata causarem cisticercose no homem, conforme admitiram Santos (1996) e outros autores citados por Pardi et al. (2001).

Quanto à identificação de C. bovis nos diversos sítios anatômicos estudados, mais uma vez destaca-se a importância de se tornar rotina nos matadouros, os exames de esôfago e fígado, pois os resultados encontrados na PCR confirmaram o diagnóstico ambulatorial feito nessas localizações.

Pelo exposto, fica evidente que o controle epidemiológico desta fascinante parasitose, que transcende ao tempo e ao espaço, representa um importante desafio para as autoridades sanitárias e políticas, notadamente em regiões com intensa atividade agropecuária e precárias condições de saneamento básico e educação sanitária.

\section{CONCLUSÕES}

O diagnóstico ambulatorial da cisticercose, nos diversos sítios anatômicos de bovinos inspecionados foi confirmado tanto pelo exame histopatológico como pela técnica da PCR.

Os exames do fígado e do esôfago devem ser incluídos na rotina de inspeção, uma vez que foram sítios de ocorrência de Cysticercus bovis.

0 exame histopatológico das lesões nodulares abscedadas e calcificadas, com vistas à observação dos corpúsculos calcários, deve ser realizado de forma minuciosa em face da escassez de tais estruturas, em virtude da evolução do processo de interação parasita-hospedeiro.

A utilização do HDP2F1R1-PCR permitiu a confirmação do $C$. bovis em cistos viáveis, viabilizando sua aplicação como método auxiliar de diagnóstico.

A extração de DNA de C. bovis vivo, pela fervura em água, foi um método exeqüível, com bons resultados.

Houve diferença significativa $(\mathrm{p}<0,05)$ entre as freqüências encontradas tanto em relação à condição morfológica, quanto aos sítios anatômicos pesquisados, indicando que os valores observados não foram devidos ao acaso.

\section{REFERÊNCIAS}

Abdussalam M. 1974. El problema de la teniasis y la cisticercosis. Anais 7a Reunião Interamericana a Nível Ministerial sobre el Control de la Fiebre Aftosa y otras Zoonosis, Trinidad. OPAS/OMS, Trinidad.

Agapejev S. 1996. Epidemiology of neurocysticercosis in Brazil. Revta Inst. Med. Trop., São Paulo, 38(3):207-216.

Alves T.A.G. 2000. Prevalência da cisticercose em bovinos e suínos no Município de Camboriú_Monografia de Especialização, Centro de Ciências Agroveterinárias, Universidade do Estado de Santa Catarina, Lages. Disponível em <http://www.cidasc.sc.gov.br/Artigo Taisa.htm> Acesso em 20 jan. 2005.

Barriga 0.0. 1995. The eosinophils in parasitic infections. Parasitol. Today 19:44-56.

Bowles J. \& McManus D. 1994. Genetic characterization of the Asian Taenia, a newly described taeniid cestode of humans. Am. J. Trop. Med. Hyg. 50(1):33-44.

Brasil 1971. Padronização de Técnicas, Instalações e Equipamentos. I. Bovinos. Lei 1283 de 18.12.1950, Ministério da Agricultura Pecuária e Abastecimento, Brasília. 240p.
Brasil 1997. Regulamento de Inspeção Industrial e Sanitária de Produtos de Origem Animal. Lei 1283 de 18/12/1950, Regulamentada pelo Decreto 30691 de 20/03/1952 e alterado pelo Decreto 1255 de 25/06/1962. RIISPOA, Ministério da Agricultura.

Bundza A., Finley G.G. \& Easton K.L. 1988. An outbreak of cisticercosis in feedlot cattle. Can. Vet. J. 29:993-996.

Costa R.F.R., Santos I.F. \& Tortelly R. 2002. Cisticercose hepática bovina. Anais XXIX Congresso Brasileiro de Medicina Veterinária, XV Congresso Estadual de Medicina Veterinária, IV Congresso de Medicina Veterinária do Conesul e I Congresso Estadual da Anclivepa, Gramado, RS, p.57.

Costa R.F.R., Santos I.F., Nascimento E.R. \& Tortelly R. 2005. Pesquisa de cisticercose em corações de bovinos comercializados na cidade de Nova Friburo/RJ, inspecionados pelas técnicas de Santos e do fatiamento. Higiene Alimentar $\_$São Paulo, 19(129):82-87.

Costa R.F.R., Santos I.F., Nascimento E.R. \& Tortelly R. 2006. Caracterização das reações inflamatórias em corações de bovinos comercializados na cidade de Nova Friburgo/RJ. Revta Bras. Ciênc. Vet. 13(2):76-79.

Dias R.M.D.S., Silva M.I.P.G., Mangini A.C.S., Vellosa S.A.G., Torres D.M.A.G.V., Silva R.M. \& Vaz A.J. 1991. Ocorrência de Taenia sp. na população atendida no Laboratório Central Adolfo Lutz, São Paulo, SP, Brasil (1960/1989). Revta Inst. Med. Trop., São Paulo, 33(2):147-151.

Eom K.S. \& Rim H.J. 1993. Morphologic descriptions of Taenia asiatica sp. Korean J. Parasitol. 31(1):1-6.

Eom K.S., Rim H.J. \& Geerts S. 1992. Experimental infection of pigs and cattle with eggs of Asian Taenia saginata with special reference to its extrahepatic viscerotropism. Korean J. Parasitol. 30(4):269-275.

Esteves F.M., Silva-Vergara M.L. \& Carvalho A.C.F. B. 2005. Inquérito epidemiológico sobre teníase em população do Programa Saúde Família no Município de Uberaba, MG. Revta Soc. Bras. Med. Trop. 38(6):530-531.

Fan P.C., Chung W.C., Lin C.Y. \& Wu C.C. 1990. Experimental infection of Thailand Taenia (Chiengmai strain) in domestic animals. Int. J. Parasitol. 20(1):121-123.

Fan P.C., Lin C.Y., Chen C.C. \& Chung W.C. 1995. Morphological description of Taenia saginata asiatica (Cyclophyllidea:Taeniidae) from man in Asia. J. Helminthol. 69:299-303.

Flavigna-Guilherme A.L., Silva K., Araújo S.M., Tobias M.L. \& Flavigna D.L.M. 2006. Cisticercose em animais abatidos em Sabáudia, Estado do Paraná. Arq. Bras. Med. Vet. Zootec. 58(5):950-951.

Fukuda R.T. 2003. Contribuição ao estudo da epidemiologia da cisticercose bovina na região administrativa de Barretos: aspectos ambientais e econômicos. Tese de Doutorado, Faculdade de Ciências Agrárias e Veterinárias, Universidade Estadual Paulista, Jaboticabal. 127p.

Fukuda R.T., Santos I.F. \& Andrade C.R. 1998. Estudo comparativo entre técnicas de inspeção do diafragma para o diagnóstico da cisticercose bovina. Higiene Alimentar 12(55):51-62.

Galán-Puchades M.T. \& Mas-Coma S. 1996. Considering Taenia asiatica at species level. Parasitol. Today_12(3):123.

González L.M., Estrella M., Harrison L.J.S., Parkhouse R.M.E. \& Garate T. 2000. Differential diagnosis of Taenia saginata and Taenia solium infection by PCR. J. Clin. Microbiol. 38(2):737-744.

González L.M., Estrella M., Puente S., López-Velez R., Hernández M., Sciutto E., Harrison L.J.S. \& Parkhouse R.M.E. 2002a. PCR tools for the differential diagnosis of Taenia saginata and Taenia solium taeniasis/cysticercosis from different geographical locations. Diagn. Microbiol. Infect. Dis. 42:243-249.

González L.M., Estrella M., Sciutto E., Harrison L.J.S., Parkhouse R.M.E. \& Garate T. 2002b. Differential diagnosis of Taenia saginata and Taenia solium infections:from DNA probes to polymerase chain reaction. Trans. Royal Soc. Trop. Med. Higiene 96(Supl.1 S1):243-250.

González L.M., Estrella M., Morakote N., Puente S., De Tuesta J.L.D., Serra T., López-Velez R., McManus D.P., Harrison L.J.S., Parkhouse R.M.E. \& Garate T. 2004. Differential diagnosis of Taenia saginata and Taenia saginata asiatica taeniasis through PCR. Diagn. Microbiol. Infect. Dis. 49:183-188.

Gibson T.E. 1959. The identification of Cysticercus bovis with special reference to degenerate cysticerci. Ann. Trop. Med. Parasitol. 53:25-26. 
Gusso R.L.F., Monozzo J.C., Thomaz-Soccol V., Camargo N.J. \& Lopes C.M. 2000. Experimental infection of cattle with eggs of Taenia solium. Archs Vet. Sci. 5:23-27.

Jardim E.A.G.V. 2006. Anátomo-histopatologia e PCR na identificação de cisticercos de bovinos. Tese de Doutorado, Escola de Veterinária da Universidade Federal de Goiás, Goiânia. 79p.

Jardim E.A.G.V., Linhares G.F.C., Torres F.A.G. \& Araújo J.L.B. 2006. Diferenciação específica entre Taenia saginata e Taenia solium por ensaio de PCR e duplex-PCR. Ciência Rural 36(1):166-172.

Kelly W.R. 1997. The liver and biliary system: helminthic infections of liver and bile ducts, p.319-406. In: Jubb K.V.F., Kennedy P.C. \& Palmer N. (Eds), Pathology of Domestic Animals. Vol.2. $4^{\text {th }}$ ed. Academic Press, San Diego. 747p.

Logt P.B. \& Gottstein B. 2000. Unidentified parasitic cysts in cattle. Vet. Rec. 146:610-612.

Machado A.B.B., Pialarisi C.S.M. \& Vaz A.J. 1988. Cisticercose humana diagnosticada em hospital geral, São Paulo, SP (Brasil). Revta Saúde Pública 22(3):240-244.

Manhoso F.F.R. 1996. Prevalência de cisticercose bovina em animais abatidos no município de Tupã, SP (1992-1993). Higiene Alimentar 10(45): 44-47.

McCool C.J. 1979. Distribution of Cysticercus bovis in lightly infected young cattle. Aust. Vet. J. 55:214-216.

McManus D.P. \& Bowles J. 1994. Asian (Taiwan) Taenia: species or strain? Parasitol. Today 10(7):273-275.

Mendes E.C., Silva S.S., Fonseca E.A.L., Souza H.R.R. \& Carvalho R.W. 2005. A neurocisticercose humana na Baixada Fluminense, Estado do Rio de Janeiro, Brasil. Arqs Neuropsiquiatria 63(4):1058-1062.

Monlux S.W. \& Monlux A.W. 1972. Atlas of Meat Inspection Pathology. Department of Agriculture, Washington, DC.

Pardi M.C., Santos I.F., Souza E.R. \& Pardi H.S. 2001. Ciência, Higiene e Tecnologia da Carne. Vol.1. 2ª ed. Editora da Universidade Federal de Goiás, Goiânia. 623p.

Pawlowski Z. \& Schultz M.G. 1972. Taeniasis and Cysticercosis (Taenia saginata). Adv. Parasitol. 10:269-343.
Santos I.F. 1982. Nova técnica de exame do coração na rotina de inspeção da cisticercose bovina. Higiene Alimentar_1(2):90-103.

Santos I.F. 1984. Diagnóstico da cisticercose bovina em matadouros: novas técnicas de exame de esôfago e diafragma. Tese de Doutorado, Faculdade de Veterinária, Universidade Federal Fluminense, Niterói, RJ. 127p.

Santos I.F. 1993. Um modelo de inspeção para a detecção da cisticercose muscular bovina em matadouros. Tese de Concurso para Professor Titular, Departamento de Tecnologia de Alimentos, Universidade Federal Fluminense, Niterói, RJ. 73p.

Santos R.E.V., Santos I.F. \& Bonisson J.C. 2003. Estudo comparativo entre a técnica post mortem de Santos e a do serviço de inspeção estadual para detecção de Cysticercus bovis em matadouros no Estado do Rio de Janeiro, Brasil. Revta Bras. Ciênc. Vet. 10(3):175-181.

Sterba J. \& Dyková I. 1978a. Tissue reaction of the skeletal muscles of cattle both to a spontaneous and experimental infection with Cysticercus bovis. Folia Parasitol., Praha, 25:347-354.

Sterba J. \& Dyková I. 1978b. Tissue reaction of the liver of cattle to an artificial or natural infection with Cysticercus bovis. Folia Parasitologica (Praha). 25:143-146.

Sterba J., Dyková I. \& Machnicka B. 1979. Tissue reaction in the heart of cattle with a spontaneous and artificial Cysticercus bovis infection. Folia Parasitol., Praha, 26:27-33.

Takayanagui O.M. \& Leite J.P. 2001. Neurocisticercose. Revta Soc. Bras. Med. Trop. 34(3):283-290.

Tortelly R. 2003. Lesões em fígados de bovinos sob Inspeção Sanitária e sua importância em Saúde Pública. Tese de Doutorado, Instituto de Veterinária, Universidade Federal Rural do Rio de Janeiro, Seropédica, RJ. 95p.

Yamasaki H., Nakao M., Sako Y., Nakaya K., Sato M.O., Mamuti W., Okamoto M. \& Ito A. 2002. DNA differential diagnosis of human taeniid cestodes by base excision sequence scanning thymine-base reader analysis with mitochondrial genes. J. Clin. Microbiol._40(10):3818-3821.

Yamasaki H., Allan J.C., Sato M.O., Nakao M., Sako Y., Nakaya K., Qiu D., Mamuti W., Craig P.S. \& Ito A. 2004. DNA differential diagnosis of taeniasis and cysticercosis by multiplex PCR. J. Clin. Microbiol. 42(2):548-553. 